\title{
STRESS AND COMPRESSIBILITY CALCULATION IN SUBSOIL OF HIGH EMBANKMENTS AND EFFECTIVENESS OF SPEEDING UP SUBSOIL CONSOLIDATION
}

When designing a project of speeding-up consolidation of subsoil of high embankments, there are some influences that cannot be missed. Especially in geotechnical engineering, we have to work with influences and uncertainties that have origin in geological space and surveying possibilities. On a practical example we present a possible way of subsoil stress and compressibility calculation and influence of different input data on necessary time of $90 \%$ consolidation of subsoil of one leg of a high embankment that has impact also on design distance and amount of sand piles or geodrains.

\section{Introduction}

A current need of constructing highways is very urgent in Slovakia. As the direction and altitude leading severity are very variable, we have very often to face problems related to the building of the highway embankment on soft soils.

Besides the questions related to the stability of embankment body and subsoil, there has to be solved also questions of embankment settlement (subsoil compressibility) magnitude and settlement speed. In the case of subsoil with a very low oedometric modulus and permeability (e.g. high plasticity clay $\mathrm{CH}$ ), compressibility of subsoil has a large magnitude (e.g. about $400 \mathrm{~mm}$ and more) and time of reaching $100 \%$ consolidation (to finish compressibility) is very long (e.g. about 180 years). We can not lay out the pavement on the embankment crown without some remedial operations because, on one hand - the pavement will be damaged by an excessive subsoil deformation. On the other hand, it is impossible to wait so long (until the settlement has been finished) and to lay out the pavement then. In such cases, the designer may require speeding up embankment subsoil consolidation, e.g. reach $90 \%$ consolidation within the period of 1 year, i.e.- after 1 year the pavement can be laid out without any risk of being damaged. One solution is speeding up the embankment subsoil consolidation so it is not necessary to wait so long. There are many methods for speeding up the consolidation- sand drains, prefabricated drains = geodrains, trenching lime, cement or rock columns (- improve subsoil deformations properties, too). As the sand drains and the prefabricated drains are used in the conditions of the Slovak Republic, we deal with these methods it this paper mainly from the point of view of their effectiveness.

\section{Embankment Stability and Settlement}

The method of stabilization of soft soils with vertical drains is applied on compressible, highly saturated soils, like clay and organic soil or peat. These soils are characterized by a soft structure and a big pore capacity, normally filled with water (porewater). In the case of a heavy load as when an embankment has been placed on top of clay or peat soils, settlements could occur due to the compressibility of the soil. These settlements could bring about serious construction problems.

The load caused by the surcharge is initially carried by porewater. However, when soil is not very permeable, water pressure will gradually decrease, as the porewater is able to flow away only very slowly. Increased water pressure may cause instability of the subsoil, which, on the other hand, may create slip planes. The instability might bring decreased rate of fill placement. A vertical drainage system enables a quicker construction of the embankment without any risk of landslides. In order to increase the settlement process and the reduction of water pressure, it is necessary to decrease the flow path of the porewater. This can be achieved by installing evenly spaced vertical drains. The presence of this drainage system enables the pressurized water to flow horizontally towards the nearest drain, and freely escape. Apart from the ongoing consolidation, a vertical drainage system can be a good support in maintaining the stability of an embankment in the course and after its execution. Instability of the subsoil may be manifested in two ways:

- sliding of the slope, where a part of the dike slides downwards along a slip circle,

- squeezing of the soft soil below the embankment.

\footnotetext{
* Marián Drusa, Nguyen Giang

Department of Geotechnics, University of Žilina, Faculty of Civil Engineering, Komenského 52, 01026 Žilina, Slovak Republic,

Phone: +421-41-7634818. Fax: +421-41-7233502. E-mail: drusa@fstav.utc.sk, giang@fstav.utc.sk
} 

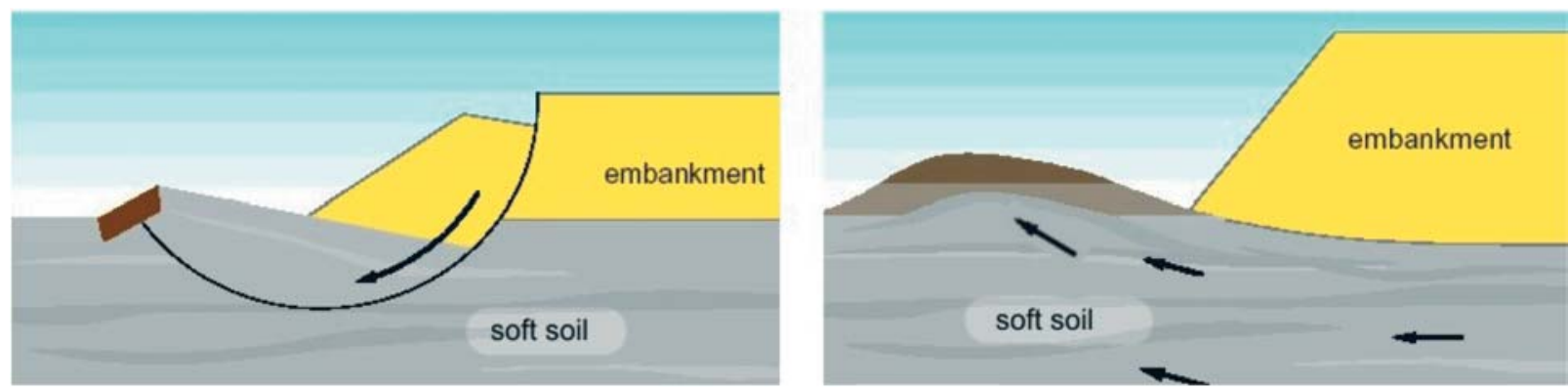

Fig. 1 Sliding and squeezing embankment

Calculation of settlement under the embankment requires calculation of stresses. For engineering practice there is possibility to use principle of superposition. This principle also allows us to split loading of trapezoidal shape to a simple rectangular and triangular strip and to apply known graphs for estimating stress in any point under loading. This way is simple, but, for calculations of the stresses in more points it is useless as it is impossible to computerize it. The second way is, to use some formulas that are not complicated, but input data, such as side angles towards the observed point varied frequently in dependence on its position. It is therefore recommended to apply the calculation method with finite element method.

For a practical example of calculations we chose one design leg of the highway embankment D1 Hričovské Podhradie - Lietavská Lúčka. The design parameters of embankment - height $7.8 \mathrm{~m}$, width at top $28 \mathrm{~m}$, slope 1:2, and total length $540 \mathrm{~m}$. Subsoil consists of high and very high plasticity clay $(\mathrm{CH}, \mathrm{CV})$ of soft and firm to stiff consistency and has the following deformation properties:

- vertical coefficient of consolidation: $c_{v}=0.015 \mathrm{~mm}^{2} \cdot \mathrm{s}^{-1}$ extremely from 0.001 to $0.007 \mathrm{~mm}^{2} . \mathrm{s}^{-1}$

- horizontal coefficient of consolidation $c_{h}=0.030 \mathrm{~mm}^{2} \cdot \mathrm{s}^{-1}$

- oedometric modulus $E_{\text {oed }}=2.7 \mathrm{MPa}$.

Under soft soils is an underlying stratum of impermeable claystones.

Stresses and settlements were computed by Nexis software using the program module Soilin. The Nexis is typical engineering software, which combines the FEM code for stress analysis with classic theory of strain of one dimensional compressibility. A main advantage of the Soilin module is interaction with subsoil through Winkler-Pasternak's model, characterized by the constants $C_{1}$ and $C_{2}$. By theory of virtual work we can write the condition for equilibrium in a vertical direction:

$$
C_{1} w+C_{2} \Delta w-q=0
$$

where: $C_{1}\left[\mathrm{MN} \cdot \mathrm{m}^{-3}\right]$ and $C_{2}\left[\mathrm{MN} \cdot \mathrm{m}^{-1}\right]$ are constants of subsoil model and are defined by the formulas:

$$
C_{1}=\int_{0}^{h} E_{\text {oed }}\left(\frac{\partial \psi}{\partial z}\right) d z ; C_{2}=\int_{0}^{h} G \psi^{2} d z
$$

where: $E_{\text {oed }}$ is oedometric modulus and $G$ shear modulus, and $\psi$ is function of vertical deformation of subsoil.
In our case we used a model of geoplate $=$ reinforced layer of gravel by geogrids of the thickness of $600 \mathrm{~mm}$, which carried out dead-weight of embankments being interacted with subsoil. The geoplate was defined by the unit weight $2000 \mathrm{~kg} \cdot \mathrm{m}^{-3}$, Young's modulus $E=150 \mathrm{MPa}$, and Poisson's ratio 0.2. In order to obtain correct results of interaction it is very important to have defined geological profile to an adequate depth, and to have right starting values of the subsoil constants. The parameters of soils used in the computational model are presented in Tab. 2, for estimation of settlement layers were divided into thinner layers. The final result is shown in Fig. 2 with settlement uz from -54.2 to $-428.4 \mathrm{~mm}$.

Table 2

\begin{tabular}{|r|r|r|r|r|r|r|}
\hline $\begin{array}{c}\text { Geolo- } \\
\text { gical } \\
\text { layer }\end{array}$ & $\begin{array}{c}\text { Depth } \\
{[\mathrm{m}]}\end{array}$ & $\begin{array}{c}\text { No. of } \\
\text { layers }\end{array}$ & $\mathrm{E}_{\text {def }}[\mathrm{Pa}]$ & $\begin{array}{c}\text { Poisson's } \\
\text { ratio }\end{array}$ & $\begin{array}{c}\text { Gama } \\
{\left[\mathrm{N.m}^{3}\right]}\end{array}$ & $\begin{array}{c}\text { coeff } \\
\mathrm{m}\end{array}$ \\
\hline 1 & 9.4 & 10 & 1500000.0 & 0.42 & 20000.0 & 0.01 \\
\hline 2 & 20.0 & 7 & 10000000.0 & 0.25 & 22000.0 & 0.30 \\
\hline 3 & 30.0 & 5 & 35000000.0 & 0.15 & 23000.0 & 0.35 \\
\hline
\end{tabular}

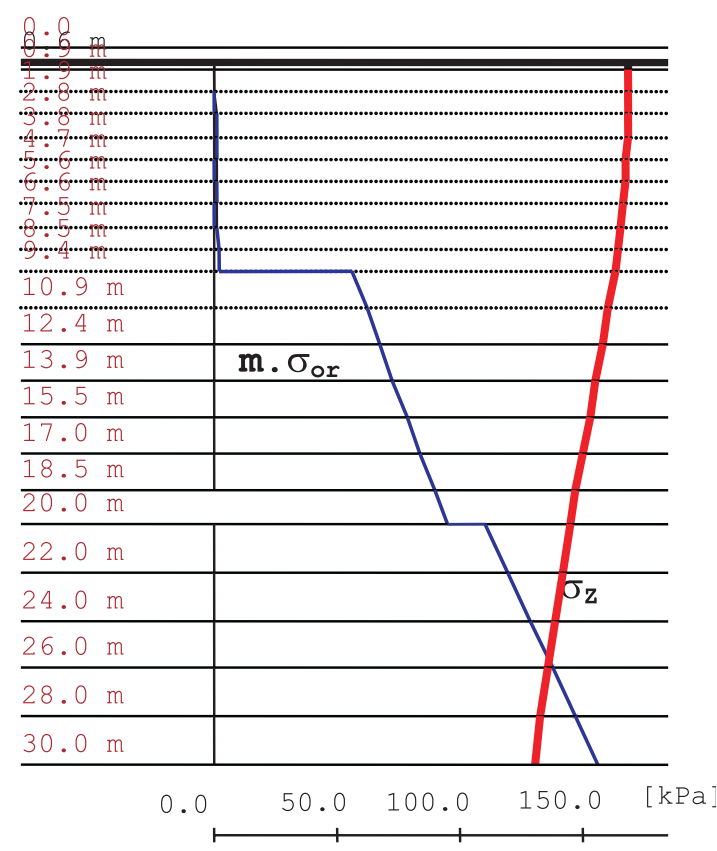

Fig. 3 Stress and structural resistance under center of embankment 

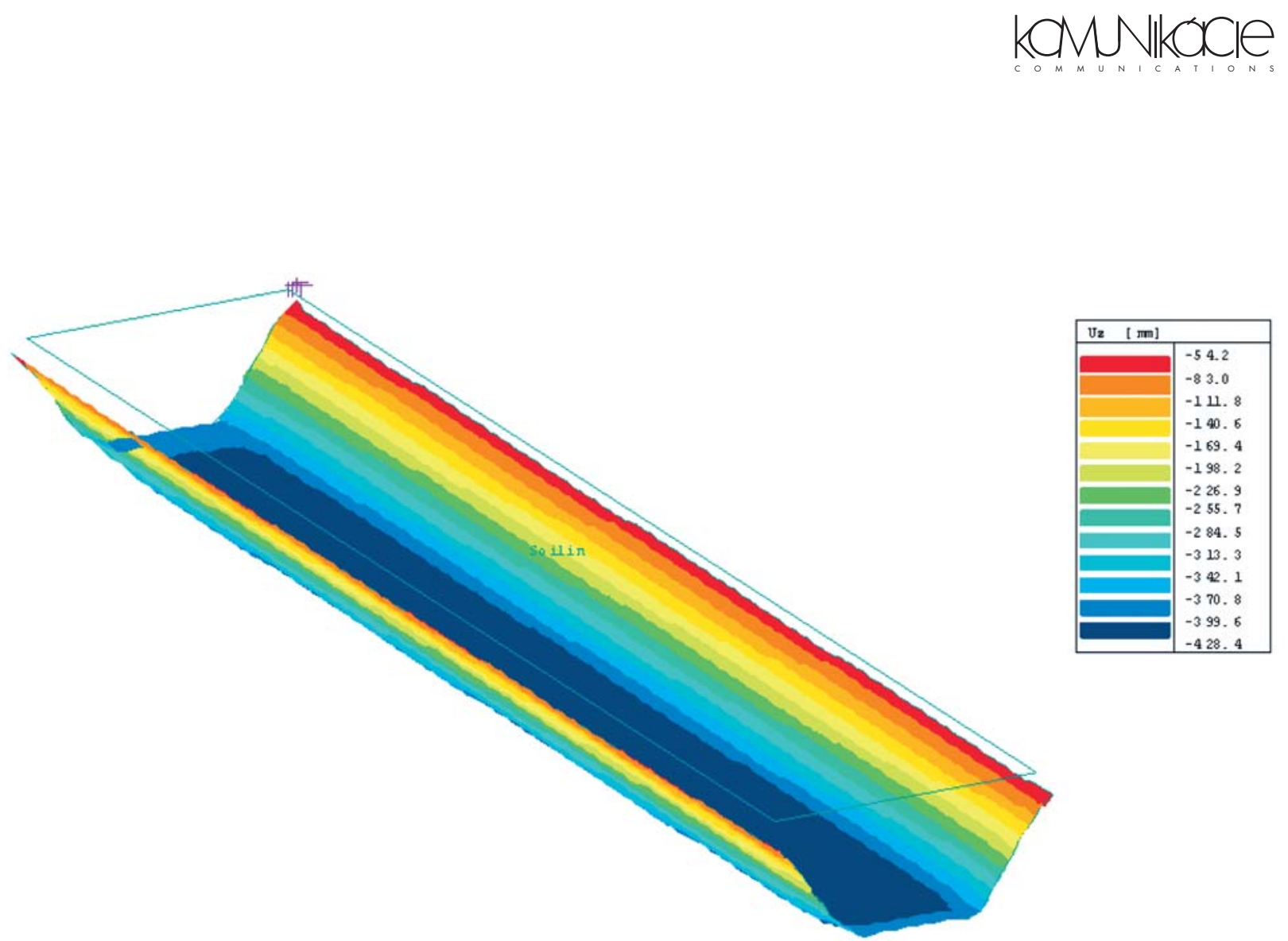

Fig. 2 Result of settlement calculation

An active zone under the embankment is deep and stress has influence on compressibility up to the depth of $25 \mathrm{~m}$, Fig. 3 .

\section{The Principle of Speeding up Embankment Subsoil Consolidation}

From history we know methods of speeding up the consolidation. The prefabricated vertical drains were used for the first time in Sweden in 1937. The drains were manufactured in cardboard, so-called cardboard wick. Approx. 10 years earlier, sanddrains were developed in California in order to expedite consolidation. Especially in the Netherlands, sanddrains have been applied in a large scale since 1950. The first synthetic drain was introduced in 1972 for a building pit at the Hemweg power station in Amsterdam. Its development was then accelerated. Synthetic drains are superior to sanddrains because of their flexibility and better filtration, and they became a formidable competitor.

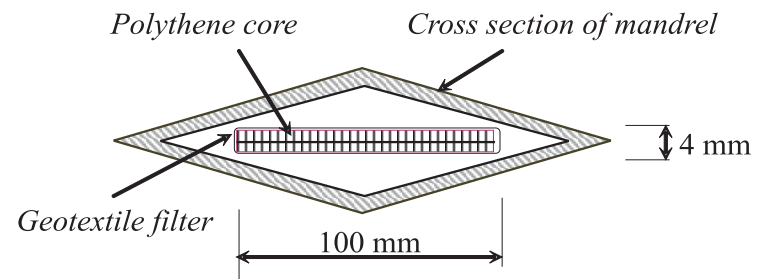

Fig. 4 Schematic cross section of prefabricated band-shaped drain with mandrel

The slow rate of consolidation in saturated clays of low permeability may be accelerated by means of vertical drains (Fig. 4).
Consolidation then depends mainly on horizontal radial drainage, resulting in faster dissipation of excess porewater pressure. The vertical drainage becomes less important, then.

The traditional method of installing vertical drains is by driving boreholes through the clayey layer and backfilling with a suitably grade sand. Typical diameters are from 200 to $400 \mathrm{~mm}$ and drains are installed into depths over $30 \mathrm{~m}$. The sand should be capable of allowing the efficient drainage of water without permitting fine soil particles to be washed in. Prefabricated drains are also used and are generally cheaper than backfilled drains. One such type consists of a filter stocking, generally of woven polypropylene, filled with sand of typical diameter of $65 \mathrm{~mm}$. Compressed air is used to ensure that the stocking is completely filled with sand. This type of drain is very flexible and is usually unaffected by any lateral ground movements. Another type of prefabricated drain is the band drain, consisting of a flat plastic core with drainage channels, surrounded by a thin layer of filter fabric: the fabric must have sufficient strength to prevent it from being squeezed into the channels. The main function of the fabric is to prevent the passage of fine soil particles which may clog the channels in the core. Typical dimensions of the band drain are $100 \mathrm{~mm}$ by $4 \mathrm{~mm}$ and the equivalent diameter is generally assumed to be the perimeter divided by $\pi$.

Prefabricated drains are installed either by insertion into prebored holes or by placing them inside a mandrel or casing which is then driven or vibrated into the ground (Craig, 1995). The consolidation process in axial-symmetrical state can be calculated by the methods presented by Barron (1948) and Hansbo (1972, 1979). In these methods, linear stress-strain relationships and constant soil parameters are assumed in the deformation process, as well as constant vertical surface displacements throughout the drained 
area (Jamiolkowski et al 1983). The effect of secondary compression is also neglected. With these assumptions, the equation of consolidation becomes:

$$
\frac{\partial u}{\partial t}=c_{h} \cdot\left(\frac{\partial^{2} u}{\partial r^{2}}+\frac{1}{r} \cdot \frac{\partial u}{\partial r}\right)+c_{v} \frac{\partial^{2} u}{\partial z^{2}}
$$

where: $c_{v}, c_{h}$-coefficient of vertical and horizontal consolidation $\left(\mathrm{m}^{2} /\right.$ year $)$,

$u \quad$ - is excess pore pressure $(\mathrm{kPa}), t-$ is time of consolidation (years),

$z \quad$ - is vertical space coordinate $(\mathrm{m})$, and $r$ is radial space coordinate $(\mathrm{m})$

The degree of consolidation is defined as degree of dissipation of the excess pore pressure; it can be expressed as (Carillo. 1942):

$$
U=U_{h}+U_{V}-U_{h} \cdot U_{V}
$$

In some literature the formula (4) is written as:

$$
(1-U)=\left(1-U_{h}\right) \cdot\left(1-U_{V}\right)
$$

The degree of vertical consolidation $U_{v}$ is calculated according to Terzaghi's theory and the degree of horizontal consolidation $U_{h}$ is calculated from Barron (1948):

$$
U_{h}=1-\exp \left(-8 T_{h} / \mu\right)
$$

where $T_{h}$ is time factor:

$$
\begin{aligned}
& T_{h}=c_{h} \cdot t / D^{2} \\
& \mu=\frac{n^{2}}{n^{2}-1} \cdot\left(\ln n-\frac{3}{4}+\frac{1}{n^{2}}-\frac{1}{4 \cdot n^{2}}\right) \\
& n=\frac{D}{d}
\end{aligned}
$$

where $D$ is diameter of dewatered soil cylinder (m) and $d$ is drain diameter $(\mathrm{m})$.

For calculation of the degree of total consolidation $U$, degree of vertical consolidation $U_{v}$ is required, then the degree of horizontal consolidation $U_{h}$ will be calculated (equation (6) or (7)) For the chosen drain diameter $d$ the dewatered soil cylinder $D$ can be calculated (see equations (6) up to (9)). The final spacing of drains in a square pattern can be obtained:

$$
S=D / 1.13
$$

Spacing of drains in a triangular pattern is:

$$
S=D / 1.05
$$

\section{The Calculation of Effectiveness of Drains}

For the selected leg of highway embankment D1 Hričovské Podhradie - Lietavská Lúčka the time needed for reaching $90 \%$ consolidation of subsoil was calculated, then necessary distance of sand drains diameter of $400 \mathrm{~mm}$ and prefabricated drains (dimension $100 \mathrm{~mm}$ by $4 \mathrm{~mm}$ ) in a square pattern. At last costs of speeding up subsoil consolidations were evaluated. The results are introduced in the following tables 4,5 , and 6 .

Time (in years) to reach $90 \%$ consolidation

Tab. 4 of subsoil of highway embankment depending on its thickness

\begin{tabular}{|l|rrrr|}
\hline $\begin{array}{l}\text { Values of } c_{v} \\
\mathrm{~mm}^{2} / \mathrm{s}\left(\mathrm{m}^{2} / \text { year }\right)\end{array}$ & $10 \mathrm{~m}$ & $7.5 \mathrm{~m}$ & $5.0 \mathrm{~m}$ & $2.5 \mathrm{~m}$ \\
\hline $0.001(0.03153)$ & 2695.3 & 1516.4 & 673.8 & 168.5 \\
\hline $\mathbf{0 . 0 1 5}(\mathbf{0 . 4 7 3 0 4 )}$ & $\mathbf{1 7 9 . 7}$ & 101.1 & 44.9 & 11.2 \\
\hline $0.026(0.81990)$ & 103.7 & 58.3 & 25.9 & 6.5 \\
\hline
\end{tabular}

Necessary distance of sand pile and prefabricated

Tab. 5 drains in square pattern to reach $90 \%$ consolidation of subsoil after 1 year depending on its thickness

\begin{tabular}{|l|rrrr|}
\hline Thickness & $10 \mathrm{~m}$ & $7.5 \mathrm{~m}$ & $5.0 \mathrm{~m}$ & $2.5 \mathrm{~m}$ \\
\hline Sand piles & 1.727 & 1.733 & 1.747 & 1.806 \\
\hline Prefabricated drains & 1.110 & 1.114 & 1.125 & 1.171 \\
\hline
\end{tabular}

\section{Conclusions}

- A different way of calculation of stresses in subsoil under high embankments was presented by a FEM computational model.

- The difference in coefficient of consolidation values makes differences in time needed to reach $90 \%$ consolidation that changes in a large range (even hundred years and more) depending on soil properties (mainly coefficient of consolidation values) and soil thickness and drain path as well.

- In this case the use of prefabricated drains is more economical ( $46.6 \%$ of costs of sand drains).

Costs (in SKK) of speeding up the subsoil consolidations of highway embankment (thickness $10 \mathrm{~m}, 90 \%$ consolidation after 1 year)

\begin{tabular}{|l|rrrr|r|}
\hline Type of drains & Distance & Pieces & Unit cost & Total cost & Costs difference \\
\hline Sand piles & 1.72 & 11340 & 7000 & 79380000 & \multirow{2}{*}{42336000} \\
\hline Prefabricated drains & 1.11 & 27440 & 1350 & 37044000 & \\
\hline
\end{tabular}




\section{References}

[1] KOLÁŘ V., NĚMEC I.: Contact Stress and Settlement in the Structure - Soil Interface. Study ČSAV 16.91, ACADEMIA Praha, 1991.

[2] HARTLÉN J., WOLSKI W.: Embankments on organic soils. Elsevier. Amsterdam, 1996.

[3] CRAIG R. F.: Soil Mechanics. Fifth edition. Publisher Chapman \& Hall, 1991.

[4] LANCELLOTA R.: Geotechnical Engineering, Balkema Rotterdam 1995.

[5] KLABLENA P., MIČA L.: Driven compacted-in-place sand-gravel piers. $7^{\text {th }}$ International Conference with Exhibition on Piling and Deep Foundations, Vienna, p. 5.23.1-4, 1998.

[6] MIČA, L.: Stabilization of the subsoil with using stiff integral geogrids, In $4^{\text {th }}$ International Conference on Ground Improvement Techniques, Kuala Lumpur, Malaysia, CI-PREMIER PTE LTD, 2002, p. 545 - 549. 